Revista Iberoamericana, Vol. LXXVI, Núm. 232-233, Julio-Diciembre 2010, 957-971

\title{
LA TEOLOGÍA POLÍTICA DE SOR JUANA INÉS DE LA CRUZ
}

\author{
POR \\ DARDo SCAVINO \\ Universidad de Bordeaux
}

Corría el año de 1680 cuando la Iglesia Metropolitana de México le encomendó a Sor Juana Inés de la Cruz la concepción de una serie de lienzos alegóricos destinados a ornar un arco triunfal en honor de los futuros virreyes: el Marqués de la Laguna y su esposa María Luisa (Wissmer 11). La monja debía redactar además dos explicaciones de estas alegorías barrocas: una, en verso, que sería recitada ante las autoridades a modo de bienvenida; la otra, en prosa, que una imprenta de la ciudad publicaría unas semanas más tarde junto con la primera. Así nació el Neptuno alegórico, océano de colores, simulacro político, un texto en donde pululan las citas de autores latinos e incluso los lemas y los epigramas que la propia religiosa escribió con desenvoltura en la lengua de Virgilio; un texto en donde la poeta, como lo notó Alberto Salceda, no cesa de jugar con los equívocos entre las significaciones castellanas y latinas de algunas expresiones claves. ${ }^{1}$

El Neptuno alegórico de Sor Juana Inés de la Cruz ha sido objeto de varias interpretaciones, entre las cuales se destacan los ensayos de José Pascal Buxó (2007), de Cristina Beatriz Fernández (1998), de Verónica Grossi (2007), de Gregorio Hinojo (2003) y las extensas páginas, claro, que Octavio Paz le consagra en Las trampas de la fe (1982). La lectura que proponemos en este artículo introduce, no obstante, dos novedades: la primera concierne el método; la segunda, el objeto.

A nuestro entender, las alegorías del Neptuno obedecen a un mecanismo análogo a la retórica del sueño, retórica comparable, según Freud, con los procedimientos del acertijo gráfico, el jeroglífico y el pictograma (Freud 307). Jean Bottéro recordaba que

\footnotetext{
1 Se trataba de un ejercicio corriente en Sor Juana. Además de varios epigramas en latín, la monja escribió un diálogo jocoso en donde juega con las homofonías entre el español y el latín eclesiástico (241), poemas en español en los cuales intercala latines estudiantiles (249) o citas de la Vulgata (290), parodias de centones con citas de Virgilio (258) e incluso un hexasílabo dedicado a la Virgen que escribe, como dice el padre Méndez Plancarte, en un «híbrido de latín y castellano» (252). Como se ha vuelto habitual en los estudios sorjuaninos, ponemos entre paréntesis el número de texto de la edición de las Obras completas de Méndez Plancarte y Alberto Salceda, seguido de los números de línea o de verso (Sor Juana 1995).
} 
"la homofonía, corriente en la lengua sumeria, debió haberles dado a sus hablantes la idea de emplear un pictograma para designar, no el objeto que representaba, directamente o no, sino otro objeto cuyo nombre era fonéticamente idéntico o vecino” (Bottéro 27). Así, los sumerios empleaban el pictograma de la flecha (ti) para aludir a la vida, que se decía igualmente ti. Para interpretar los pictogramas o los jeroglíficos no hay que preguntarse qué simboliza la figura de la flecha sino, más sencillamente, que vocablos, fonéticamente idénticos o vecinos, se vinculan con el significante flecha. Sólo que en el caso del Neptuno estos juegos homofónicos son más bien etimológicos (sin excluir las etimologías bastardas corrientes en la tradición de Isidoro de Sevilla). Este abordaje nos permite, de paso, limitarnos a interpretar la escritura prescindiendo de la dimensión visual de los lienzos.

En lo que al objeto se refiere, no nos interesan tanto las circunstancias históricas en que el texto fuera escrito como la reconstrucción de su teología política latente. Siguiendo en este punto a Carl Schmitt, llamamos "teología política” a la secularización de los conceptos teológicos con vistas a constituir un pensamiento del Estado (Schmitt 54). De manera que, para nosotros, la apoteosis del príncipe no es sólo una amplificación retórica destinada a enaltecerlo sino también una elaboración poética tendiente a volver legible, y legítima, la soberanía del monarca.

Entre los diversos aspectos que asume esta teología política en los textos de Sor Juana, podría destacarse la elevación del príncipe a la dignidad de la causa del deseo. Tanto el Marqués de la Laguna como Carlos II aparecen asociados, en sendos poemas, con la Belleza platónica o con el hijo de Mirra, Adonis. Esta asociación explica en buena medida porque resulta difícil, si no arbitrario, establecer una distinción neta entre los poemas amorosos y políticos de la monja novo-hispana (las damas homenajeadas en sus poemas de amor eran, después de todo, dos virreinas de su tiempo: la Marquesa de la Laguna, Lysi, y la Condesa de Galve, Elvira). Esta dimensión erótica del poder podría resumirse con una sentencia: el príncipe domina a los súbditos seduciéndolos. Por cuestiones de extensión, no obstante, preferimos limitarnos a un solo aspecto de esa teología política: la equivalencia entre el poder y el origen, entre la dominación y la causa o entre el príncipe y el principio. Esta equivalencia podría resumirse con un logion sorjuanino: gracias a la hegemonía del señor, un pueblo existe.

CírCULO

Las primeras líneas del Neptuno pueden servirnos también de introducción al problema que abordamos:

Excelentísimo Señor. Costumbre fue de la antigüedad, y muy especialmente de los egipcios, adorar sus deidades debajo de diferentes jeroglíficos y formas varias; y así a

\footnotetext{
Revista Iberoamericana, Vol. LXXVI, Núms. 232-233 Julio-Diciembre 2010, 957-971 
Dios solían representar en un círculo, como lo escribe Piero Valeriano: Aegyptii Deum ex hieroglyphico circuli intelligebant, por ser símbolo de lo infinito. (400, 1-6)

La propia Sor Juana va a representarlo así en Primero sueño llamándolo, como en la tradición escolástica, prima causa, expresión que traducía ya la noción de arjê (causa, fundamento o poder) de la metafísica aristotélica:

que como sube en piramidal punta

al cielo la ambiciosa llama ardiente,

así la humana mente

su figura trasunta,

y a la causa primera siempre aspira

-céntrico punto donde recta tira

la línea, si ya no circunferencia,

que contiene, infinita, toda esencia-. (216, 404-11)

Y más adelante va a comparar este círculo con un sol

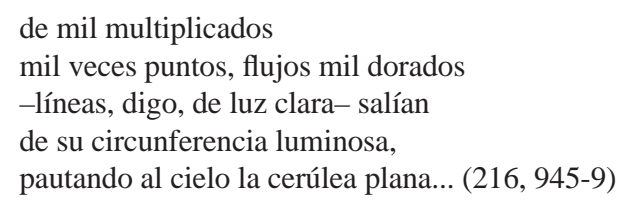

Incluso unos años más tarde, en la Respuesta a Sor Filotea, la monja va a decir que "todas las cosas salen de Dios, que es el centro a un tiempo y la circunferencia de donde salen y donde paran todas las líneas creadas” (405, 422-4). Y a una figura similar recurre en un romance dedicado, una vez más, al Marqués de la Laguna:

como a Vos, que sois el centro

glorioso donde terminan

de tan gran circunferencia

tantas bien tiradas líneas... (22, 17-20)

Como prima causa o arjê, este círculo es el conjunto más universal. Para la metafísica, en efecto, había conjuntos menos universales, como aquellos de los vegetales, los animales o los hombres. Al conjunto que abarca, sin excepción, a la totalidad de los entes, la metafísica lo llamó, como se sabe, ser. En este conjunto una cosa no cuenta como un vegetal, un animal o un hombre sino como un ente más. Y así como una cosa excluida del conjunto de los vegetales no es un vegetal, una cosa excluida del círculo de todos los entes no es un ente. No es nada. Aquello que se incluye en ese conjunto, pues,

Revista Iberoamericana, Vol. LXXVI, Núms. 232-233 Julio-Diciembre 2010, 957-971
ISSN 2154-4794 (Electrónico) 
aparece, y aquello que queda excluido desaparece. Ahora bien, como a la condición para que las cosas aparezcan se la suele llamar "luz", Sor Juana puede comparar ese círculo con un sol, como lo había hecho ya Plotino. ${ }^{2}$

La imagen del círculo resulta, en este aspecto, menos importante que el propio vocablo círculo: circum o cerco. ${ }^{3}$ Aparecer y estar cercado resultaban, para la monja, sinónimos. Una cosa aparece a condición de estar incluida, o recluida, en aquel cerco. Una cosa aparece, digamos, a condición de verse determinada o delimitada. Y por eso, para la poeta, aquello que carece de terminus, o de limes, sencillamente no existe. De hecho, todavía empleamos los verbos ex-terminar o e-liminar para hablar de aquello que pasa del ser al no-ser. Y esto explica también por qué, para la monja, como para la tradición escolástica, esta circunferencia era la prima causa: gracias a ella, las cosas pasan del no-ser al ser.

Tanto Dios como el Príncipe tienen el poder de hacer aparecer las cosas cercándolas o delimitándolas (y dehacerlas desaparecer, desde luego, exterminándolas o eliminándolas). Tanto Dios como el Príncipe responden a la pregunta metafísica por excelencia, aquella que se interroga acerca de la prima causa o de la arjê: ¿por qué hay algo en lugar de nada?

CETRO

Un mito narrado por la poeta en el Neptuno alegórico habla de este poder ontológico. Se trata del argumento del tercer lienzo que cuenta el origen de la isla de Delos, cuna de Apolo y Diana. La religiosa lo convierte en una alegoría profética de la ciudad de México, construida, como se sabe, en medio de una laguna: Texcoco.

Huyendo de los asedios amorosos de Júpiter, la ninfa Asteria se metamorfosea en codorniz (ortyx) pero se precipita en el mar convirtiéndose en isla: Ortigia. Ofendido por el desaire de la ninfa, Júpiter la condena a un "perpetuo movimiento" (401, 829), expresión que no significaba sólo desplazamiento sin reposo sino también "mudanza ligera" (402, 121). Alo largo de este texto, Sor Juana alude a este "perpetuo movimiento" con adjetivos como "movediza" (401, 852), "voluble” (401, 853), "titubeante” (402, 131), "vacilante” $(401,895)$, “errante” $(405,119)$ o "instable” (sic, 401, 812), o incluso con sustantivos como "conmoción” (401, 890) e "inquietud” (401, 886). Asteria, por consiguiente, no es una isla porque, para llegar a serlo, debería cesar de cambiar o de

2 “...todo se vuelve hacia él como los puntos de un círculo [kúklos] se vuelven hacia el centro [kéntron] de donde parten todas las líneas [grammaí]. El paradigma de esto es el sol: él es como un centro para la luz ligada a él y también está por todas partes...” (Sobre el primer bien, 1, 23-25). Octavio Paz prefería conjeturar que Sor Juana había tomado esta figura de la circunferencia infinita de Nicolás de Cusa (Paz 237).

3 Salvo indicación especial, las anotaciones etimológicas latinas a lo largo del artículo fueron verificadas en los diccionarios de Joan Corominas (1977), Blánquez Fraile (1975) y Félix Gaffiot (1934).

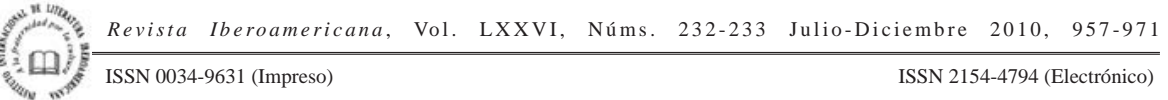


convertirse en otra. Y no es una isla, justamente, porque carece de límites o no se distingue de aquello que la rodea: el agua. "Insula dicitur terra, quae undique aquis clauditur", explica la monja (401, 871-2). Y como una isla sólo aparece, o existe, a condición de ser una isla, Asteria desaparece. De ahí que esta inestabilidad resultara indisociable de su inmersión, su ocultamiento o su desaparición, como lo sugiere la relgiosa a través de una cita de la Mitología de Natal Conti:4 "Illa enim, cum esset instabilis per illud tempus sub undis forte delitescebat" (401, 841-2). "Y como por aquel entonces ella era inestable -podríamos traducir- se encontraba oculta bajo (o borrada por) las aguas”.

La historia de Asteria se repite con su hermana, Latona. Sólo que esta ninfa cede a las efusiones del dios y queda preñada de Apolo y Diana. Cuando Juno, celosa, decrete que ningún lugar donde brillase el sol podría hospedarla para parir a sus hijos, sólo Asteria, sumergida, estará en condiciones de acogerla. En algunas versiones, no obstante, el mito cuenta que Juno ordenó que ningún lugar de tierra firme se atreviese a refugiarla, como si la oscuridad y la inconstancia, el ocultamiento y la vacilación, la desaparición y la inconsistencia, pudieran considerarse equivalentes. "Tú erras, extranjera [hospita], en la tierra -le decía Asteria a Latona en las Metamorfosis de Ovidio-, y yo en las aguas [in undis]" (VI, 190-1). Asteria, la inconstante, y Latona, la oculta, son dos nombres de aquello que, por decirlo así, no consta.

En agradecimiento por haber amparado a su madre, recuerda entonces la poeta, los recién nacidos la habrían hecho "consistente” (401, 853). Alberto Salceda anota allí que en el español latinizado de la monja novo-hispana esta última expresión significaba “fija” o "inmóvil", es decir, "inmutable" o "permanente" por oposición a la "inestabilidad" evocada por Natal Conti. Pero recordemos que el verbo consisto significaba además “residir en un lugar”, “ocupar una posición” y “presentarse”, de modo que la equivalencia entre la firmeza y la aparición -equivalencia en torno a la cual gira todo este argumentose condensaba en este vocablo. Sor Juana, de hecho, sustituye el adjetivo consistente por su sinónimo, constante, en la letra del pedestal: "isla constante" (401, 893). Delos es una isla que ya no se mueve y que, como consecuencia, consta.

Pero siguendo a Luciano, la religiosa prefiere pensar que esa constancia proviene más bien de Neptuno: "El fue, pues, el que movido a compasión por la infeliz Latona, afirmó con el tridente la movediza isla sirviendo éste de clavo a su voluble fortuna para dar estable acogida a la congojada hermosura...” (401, 851-4). Una vez afirmada o sujeta, Asteria-Latona se convierte en Delos. Y la propia Sor Juana recuerda que el sustantivo griego dêlos se traducía, en latín, por “manifestum et apparens” $(401,830)$. Esta etimología le permite entonces comparar la consistencia o, podríamos decir, la "ilatencia” de la isla con el "descubrimiento” de México: “¿Qué más manifestum et

4 Entre los tratados mitográficos que florecieron durante el siglo xvi, se encuentran la Mitología de Natal Conti (1551) y Las imágenes de los dioses de Vicenzo Cartari (1556). Sor Juana suele citarlos a ambos junto a otras fuentes clásicas como Luciano, Macrobio u Ovidio.

Revista Iberoamericana, Vol. LXXVI, Núms. 232-233 Julio-Diciembre 2010, 957-971 ISSN 0034-9631 (Impreso) 
apparens que la que tantos siglos se ocultó, como en el mar, pues temor de éste estorbaba su descubrimiento?” (401, 872-5).

Clavo

El lienzo estaba acompañado con un lema en latín: "Te clavum tenente, non nutabit” (401, 890). "Mientras la sujetes con el clavo -traduzcamos-, no sufrirá conmoción”. Porque gracias a este Neptuno-al Marqués de la Laguna-, México “espera gozar estables felicidades sin que turben su sosiego inquietas olas de alteraciones ni borrascosos vientos de calamidades" (401, 885-8). Y estas turbaciones, desde luego, no aluden solamente a cuestiones orográficas o climáticas -las periódicas inundaciones de la ciudad lacustresino también a las inclemencias políticas: la turba, el tumulto o la "conmoción” social. Por eso Sor Juana añade en el pedestal esta letra castellana:

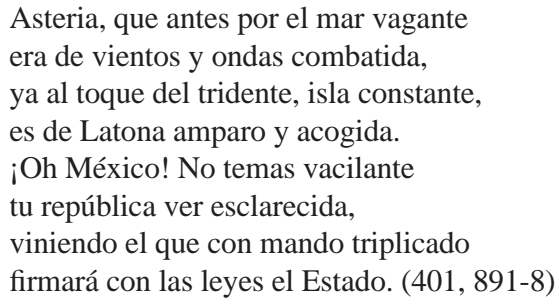

Salceda anota que "firmar" significa aquí afirmar, en el sentido de afianzar o consolidar, y podríamos añadir que el "mando triplicado" (en alusión al tridente de Neptuno) son los tres títulos reunidos por el virrey: Gobernador, Capitán General y Presidente de la Real Audiencia. Pero si el tridente se convierte en "clavo", se debe a que el sustantivo pax provenía del verbo pango cuya singnificación es "clavar”, "fijar” o "establecer". La función del soberano consiste en establecer la paz, el "sosiego" o la “quietud”, conjurando "turbaciones” o "alteraciones”. El soberano, digamos, establece el pagus dando pautas (de pactum, una vez más, participio pasado de pango). Y establecer un pagus significaba, antes que nada, fijar el limes, el terminus, el fines o el circum. Delimitar, determinar, definir o cercar una región es la tarea regia por excelencia. Porque algo no comienza a ser una cosa -una cosa firme o constante- hasta que no se distingue de otra. Incluso podría afirmarse que algo empieza cuando termina, porque si no hubiese terminus, no aparecerían las cosas.

Sor Juana ya había aludido a esta determinación en la explicación del segundo lienzo. Allí le sugería al Marqués que abriera, durante su administración, un canal por donde pudiera "fluir" la laguna para impedir las "inundaciones" (in undis, recordémoslo, era la expresión empleada por Ovidio para referirse a la situación de Asteria):

Revista Iberoamericana, Vol. LXXVI, Núms. 232-233 Julio-Diciembre 2010, 957-971
ISSN 2154-4794 (Electrónico) 


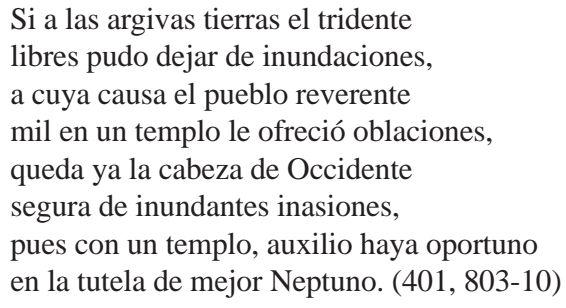

La poeta juega entonces con la doble significación del sustantivo templum: lugar de culto y espacio delimitado o determinado. Porque gracias a esta determinación, el príncipe impide la invasión (in vase) del exterior o la inundación (in undis) del interior. Sólo esta distinción -que hoy seguiríamos llamando "clara”- entre lo mismo y lo diferente, entre lo uno y lo otro, permite que la isla se muestre como tal o que, literalmente, ex-sista.

\section{Cláusulas}

El argumento del cuarto lienzo confirmaría esta interpretación. La alegoría muestra a los troyanos refugiándose detrás de los muros de la ciudad para protegerse del ataque aqueo. Y si Sor Juana recuerda este muro, se debe a que uno de los títulos del susodicho Marqués era Conde de Paredes. La leyenda cuenta que la muralla de esta ciudadela había sido erigida por el canto de Neptuno al son de la lira de Apolo. De modo que los troyanos,

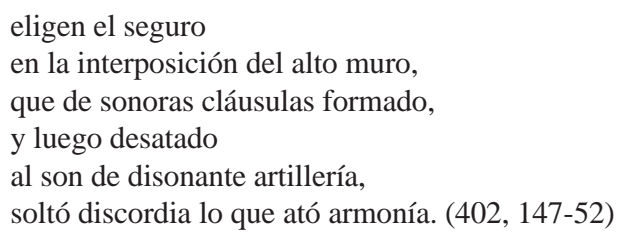

Para hablar del canto del dios la poeta escoge la expresión "sonoras cláusulas" porque este sustantivo proviene del verbo claudo, encerrar, y ésta es la función del muro, sustituto aquí del circum o del templum. Estas cláusulas se convierten, a continuación, en un lazo o una atadura que la artillería griega, "disonante”, "desata”: "soltó discordia lo que ató armonía.” Todo ocurre entonces como si, para la monja, el vocablo discordia no procediera de cor, cordis (corazón) sino de chorda (cuerda pero también lira), lo que le permite jugar con las voces discordia, disonante y desatado. La armonía o la paz suponen una concordia y ésta, a su vez, una atadura, un lazo o una reclusión de la multitud en las “cláusulas”. En esto radicaría, al fin y al cabo, la función del príncipe: sus palabras, o sus decretos, enlazan o atan a las multitudes, estableciendo la concordia, otra manera de hablar de aquella con-stancia o de aquella con-sistencia.

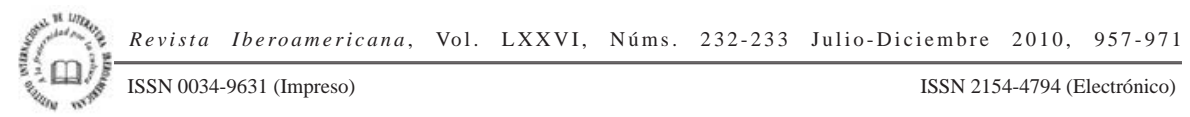


Recordemos solamente que ésta era la función que San Pablo le atribuía al Emperador romano: él con-tiene o re-tiene (katejón era el verbo griego) la anomia, impidiendo que el anómos -el Anti-Cristo- desate el lazo social (2 Tes. 2, 5-9). Y por eso Carl Schmitt sostiene que en este pasaje de la segunda epístola a los tesalonicenses se concentraba el fundamento de la doctrina cristiana del Estado (Schmitt 143). Pero el propio vocablo príncipe condensaba ya este círculo que "contiene, infinita, toda esencia”. Contracción de primus y capere, el princeps era el primer captor, el que los captura a todos, o en el cual caben (capere) los demás. De ahí que el captivus del príncipe se convirtiera en su servus: al vencido (vinctus), el príncipe le imponía un vínculo, esto es: un yugo, una cadena o un lazo.

\title{
CEnTRO
}

En las silvas recitadas aquel día ante el virrey, la explicación del tercer lienzo se presentaba de este modo:

\author{
Allí Señor, errante peregrina, \\ Delos, siempre en la playa cristalina \\ con mudanza ligera, \\ fue de su misma patria forastera, \\ pero apenas la toca \\ el Rector de las Aguas, cuando roca \\ ya en el fijo centro estriba, \\ de ondas y vientos burladora altiva; \\ que a bienes conmutando ya sus males, \\ patria es de los faroles celestiales: \\ en quien México está representada, \\ ciudad sobre las ondas fabricada, \\ que en césped titubeante \\ ciega gentilidad fundó ignorante: \\ si ya no providencia misteriosa \\ émula de Venecia la hizo hermosa \\ porque pudiese en su primera cuna \\ consagrarse al Señor de la Laguna; \\ en quien, por más decoro, \\ nace en plata Dïana y Febo en oro, \\ que a vuestras plantas postren a porfía \\ cuanto brilla la noche y luce el día. (402, 119-40)
}

En los verbos rey y virrey, Sor Juana escuchaba su antigua significación: rex, regis, proviene del verbo rego: regir. El virrey puede presentarse entonces como un "rector". Pero este rector no sólo rige sino que también e-rige, y por eso la erección de la ciudad

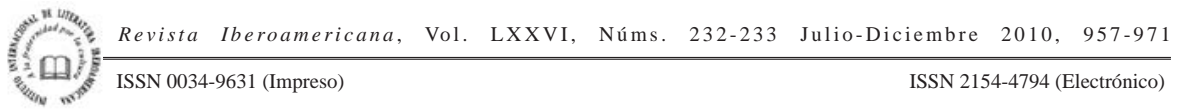


no depende aquí de sus constructores, los aztecas, sino del cetro soberano. Apenas el "Rector de las Aguas” "toca” con su tridente a Asteria-Tenochtitlán, “cuando roca / ya en el fijo centro estriba” y surge de las aguas convertida, como por arte de magia, en Delos-México. Centrum, precisamente, no significaba sólo “centro”, en el sentido de un punto equidistante de la periferia, sino también "punta” o "clavo”. Y como así se llamaba a la punta, o al brazo fijo, de los compases, pasó a denominarse centrum al centro de la circunferencia que aquél traza (de hecho, punctum tampoco significaba, en principio, “punto” sino “punta”). El centrum, en este caso, es el tridente de Neptuno -el cetro del rey o del virrey- y éste es el "fijo centro" en donde “estriba” (se apoya o se fundamenta) la isla: el punctum firmum et inconcussum como la tradición escolástica llamaba a la prima causa o a la arjê.

Hay que recordar, no obstante, que ese “cetro” es el símbolo de los decretos o los mandatos del "rector” "“firmará con las leyes el Estado”, escribía la monja a propósito del tercer lienzo, mientras que, en el cuarto, la “armonía” proviene de las “sonoras cláusulas” del dios Neptuno). Sor Juana resume esta relación entre el tridente y la palabra con la expresión “mando triplicado”. Como explica en su poema de bienvenida al Marqués, Asteria-Tenochtitlán se "encomienda” a Neptuno -se pone bajo su mando- y a partir de ese momento, cesando la “mudanza ligera”, se transmuta en Delos-México.

\section{CAYADO}

Cuando se refiere a las autoridades eclesiásticas, Sor Juana sustituye aquel cetro por un báculo o un cayado. Su función, no obstante, seguirá siendo la misma. Así, en el poema de bienvenida al Marqués de la Laguna, la monja le dice que el arco ilustrado es el preludio

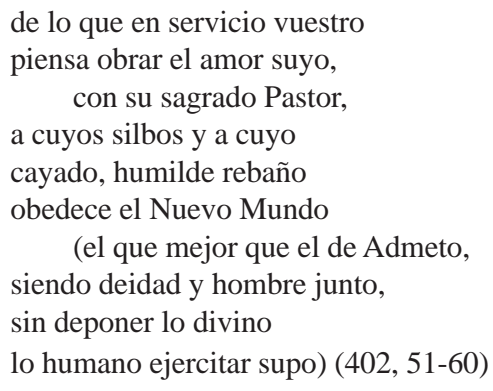

Alberto Salceda recuerda aquí que el Pastor en cuestión era el arzobispo-virrey de México, Fray Payo de Ribera, amigo y protector de Sor Juana. Y aunque el verso “siendo deidad y hombre junto" nos haría pensar más bien en Cristo, es cierto que la monja no escatima las hipérboles cuando se trata de aquel personaje. Así, en la primera Loa a los años del Rey, el Cielo en persona le canta al arzobispo-virrey:

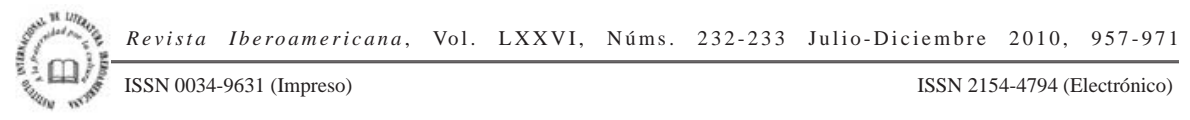




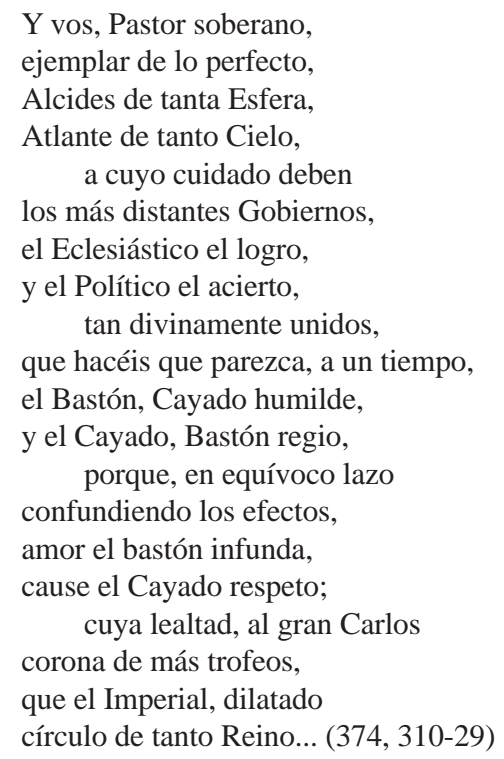

Aunque en este caso no se trate del poder político sino espiritual o religioso, Sor Juana insiste en su capacidad para reunir el rebaño disperso, o para con-gregar, precisamente, la grey, conjurando la dis-gregación. El pastor no sería sino el prefijo con- del verbo gregare, pero también, como ya vimos, de los sustantivos con-sistencia y con-stancia. La propia Sor Juana compara entonces al cayado del pastor con el batón del monarca: ambos reúnen a la multitud impidiendo la turbamulta.

Esta comparación del príncipe con un pastor provenía incluso de una tradición anterior al cristianismo. ${ }^{5}$ Ya en la Ilíada, Homero llamaba a Agamemnón poimên laôn (pastor de multitudes) y el propio vocablo nomós (ley) estaba etimológicamente vinculado con nomeús (pastor), nomeúô (apacentar) y nomê (reparto, distribución, manada, pastoreo). A Zeus se lo llamaba Nómios o Némeois cuando cuida su rebaño. Y de estos vocablos griegos proviene la apelación latina Nomius (Pastor) con que se invocaba a Apolo. Este Nomius, conjura, como en la epístola de San Pablo, la anomia. ${ }^{6}$

5 La pastoral cristiana suele autorizarse en el Evangelio de San Juan (10, 1-18). Pero como recordaba Fray Luis de León (Fray Luis 220), las alusiones al poder pastoral se remontan a los libros proféticos de la Biblia, sobre todo a Isaías $(50,11)$, Ezequiel $(24,24)$ y Zacarías $(11,16)$.

6 Acerca de la etimología del vocablo griego nomós (Benveniste 84). Sobre el problema de la anomia (Agamben 110). Foucault considera que este poder pastoral se inspira en el odelo de la pastoral cristiana, pero él mismo admite que la figura del rey como pastor se remonta a la antigüedad (Foucault 134). Foucault recuerda que, en el Político, Platón contesta esta figura del príncipe como pastor, pero el mero hecho de que la discuta, prueba que se trataba de una asociación corriente.

S. ISSN 0034-9631 (Impreso) ISSN 2154-4794 (Electrónico) 
Que esta congregación se traduzca en una manifestación de lo congregado, lo sugiere, en los versos del Neptuno, la alusión al pastor de Admeto. Este pastor era, según la mitología, Apolo. De ahí que para los romanos existiera un pastorallis Apollo: el que ilumina congregando. Y a esta iluminación se refiere Sor Juana cuando apostrofa a la ciudad exhortándola a no temer que su "república" sea "esclarecida” por quien va a venir a afirmar "las leyes del Estado" con el "mando triplicado" (401, 891-8). El esclarecimiento es la consecuencia de la sujeción de la isla con el "cetro" o con el "clavo".

Tanto los "rayos" del sol como los "radios" de la circunferencia resultan, de esta manera, extensiones de aquel cetro, del cayado o del báculo de los príncipes, como si Sor Juana estuviese reviviendo la antigua signifiación del latín radius: vara, pica o puntal. Y aquel pasaje de Primero sueño en que la poeta propone una analogía entre la circunferencia y el sol pareciera confirmar esta lectura:

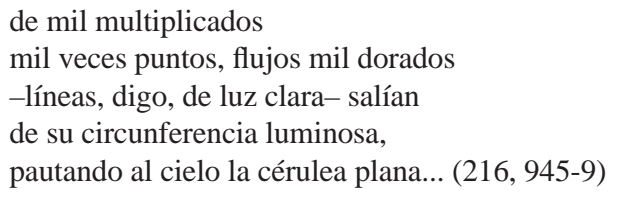

Pautar significaba trazar renglones, o rayas, sobre la página. Pero el sustantivo pauta provenía, como ya vimos, de pactum, participio de pango -en Cicerón, sin ir más lejos, encontramos las expresiones terminos pangere o fines pangere (Gaffiot 1110) para aludir a esta fijación o establecimiento de los límites-. Tanto el sustantivo pagus como su diminutivo, pagina, son lugares delimitados o determinados. Y todavía empleamos la locución pautar en el sentido de fijar los límites de una actividad o los términos de un acuerdo. De modo que la función de los rayos del sol es pautar, rayando, y esto es lo que, según la poeta, hace cuando alumbra. El pacifismo sorjuanino, podríamos decir, es un elogio de la dominación.

\section{DESCUBRIR}

Sor Juana recuerda, por cierto, que Tenochtitlán había sido “fabricada” por aquella "ciega gentilidad" (los aztecas). Pero sucede que, para la monja, esta construcción no implicaba una verdadera fundación. Fundar significa, como sugiere, "afirmar" o "estribar", y los nativos habían construido la ciudad sobre un "césped titubeante", condenándola así al "perpetuo movimiento" o a la "mudanza ligera”, a la "alteración” o a la “turbación”. Esta "inestabilidad” urbana se traducía, gracias al argumento alegórico, en una "inconstancia” civil. Porque la ciudad carecía de bases o estribos políticos sólidos, y éstos sólo no podían proporcionarlos las autoridades paganas (la "ciega gentilidad") sino el príncipe cristiano. La consolidación urbana y civil de México coincide entonces

Revista Iberoamericana, Vol. LXXVI, Núms. 232-233 Julio-Diciembre 2010, 957-971 
con su “descubrimiento" (en los sentidos de hallazgo, revelación y puesta al descubierto). Así, la poeta escribe a propósito del segundo lienzo:

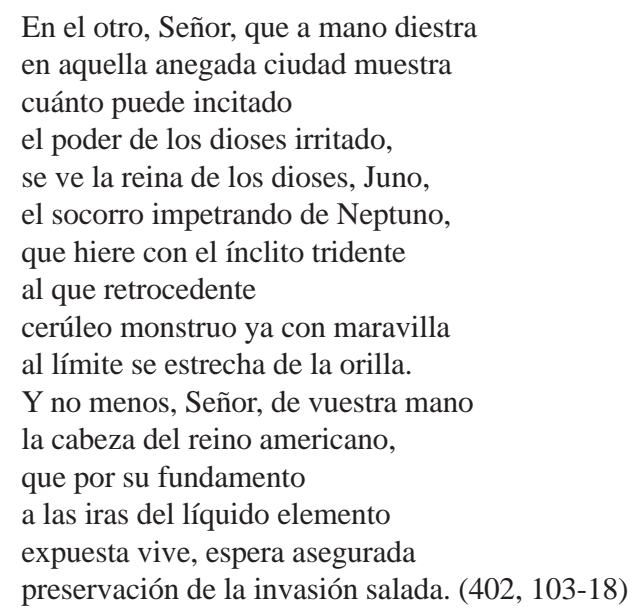

Descubrir significa entonces, para la monja, "hacer aparecer” o "exponer” haciendo retroceder el agua. Y esto sólo se logra cuando el príncipe fija los límites o establece las pautas.

Sor Juana, desde luego, estaba poniendo su pluma al servicio de la peor propaganda política porque estaba justificando, con su texto, la expoliación de las poblaciones nativas por parte del Imperio español. A esta expoliación la presenta -ya lo vimoscomo una oblación ofrecida al príncipe o con una "postración” a sus pies (equiparándola implícitamente con los sacrificios que los gentiles les hacían a sus dioses). Así deberían agradecer los nativos a los españoles por haberlos “descubierto” o por haberlos salvado -aunque parezca irónico- de la "desaparición”.

El mito sobre el surgimiento de la isla de Delos es un mito teológico-político y una narración onto-teo-lógica. El tercer lienzo, de hecho, coincide con el tercer día de la creación del Génesis cuando Dios reúne (congregentur, decía la Vulgata de San Jerónimo) las aguas para que surja la "tierra” (Gn 1, 9). La propia Sor Juana cita este pasaje en la explicación de la "Primera basa de mano siniestra": "Congregentur aquae, quae sub coelo sunt, in locum unum, et appareat arida” (401, 1469-70). En este frase se encontraba entonces aquel verbo, appareo, cuyo participio pasado, apparens, Sor Juana proponía como traducción de Delos. Pero los verbos pareo y appareo no significaban solamente presentarse, manifestarse o constar sino también estar al servicio de alguien, obedecer o someterse (un apparitor era un servidor y todavía se emplea en francés el sustantivo appariteur para aludir a un bedel o un asistente). De ahí que no

Revista Iberoamericana, Vol. LXXVI, Núms. 232-233 Julio-Diciembre 2010, 957-971
ISSN 2154-4794 (Electrónico) 
haya diferencia, para Sor Juana, entre aparecer y estar sujeto, entre manifestarse y estar clavado, entre revelarse y verse encerrado en las cláusulas. A lo largo de su obra, la monja va a comparar muchas veces la dominación del príncipe con este alumbramiento, como en estas coplas escritas en homenaje a Carlos II:

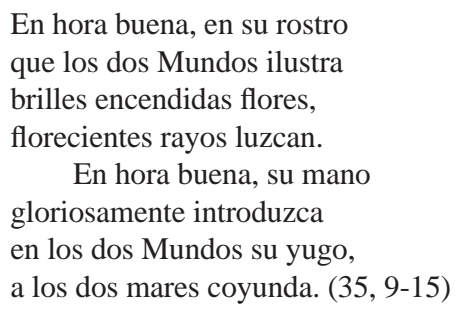

Los rayos son yugos e ilustrar es coyundar. No hay alumbramiento, para la poeta, sin sujeción, ni aparición sin avasallamiento. No hay iluminación sin inclusión en el círculo, o el cerco, del príncipe. Y si puede comparárselo con la divinidad, se debe a que ambos tienen este poder de manifestar o dar a luz.

\section{ConCLUSIÓN}

Nuestra lectura del Neptuno alegórico se limitó a un solo aspecto de su horizonte teológico-político: la equivalencia entre la causa, el fundamento y el poder, tres traducciones posibles del vocablo griego arjê (de donde provienen, como el propio Aristóteles señalaba, ${ }^{7}$ vocablos como mon-arquía u olig-arquía). Tal vez pueda parecer sorprendente hoy esta identidad entre la dominación y el engendramiento o la obediencia y la aparición, pero seguimos diciendo -y, en consecuencia, pensando- que un efecto “obedece” a una causa o que el "factor fundamental” es también el "dominante”. A este “factor” la teología lo llamaba Pater, y como era "dominante”, Dominus. Haciendo hincapié en las diferencias entre pasado y presente, el relativismo histórico nos ha inducido a olvidar las repeticiones -condición sine qua non, como lo sabía Freud, para su perpetuación-, y por eso una interpretación rigurosa de los textos del pasado no debería subestimar su dimensión oracular.

Recordemos que un autor como Ernesto Laclau sigue pensando hoy que los significantes hegemónicos no sólo representan sino que también constituyen a esa totalidad llamada “pueblo”. Y él mismo sostiene, contra Claude Lefort, que el cuerpo sublime o místico del rey -ese cuerpo que se identificaba, según Kantorowicz, con la unidad indivisible del reino-no desapareció con las sociedades democráticas: “Ese cuerpo

7 Metafísica, libro Delta, 1, 13.

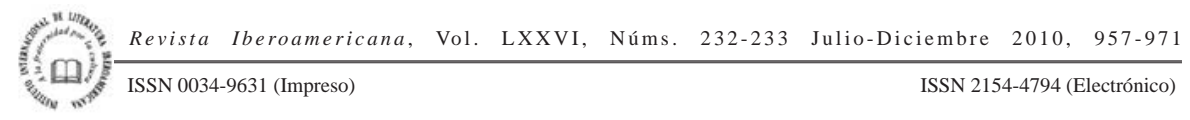


inmortal es encarnado por la fuerza hegemónica” (Laclau 215). Lo que ha cambiado con la democracia, añade el historiador argentino, es que en los Anciens Régimes "la encarnación tenía lugar en un solo cuerpo, mientras que en la actualidad transmigra a través de una variedad de cuerpos” (ibid.). Pero la lógica de la encarnación, y de la constitución política de la unidad popular, "continúa operando bajo condiciones democráticas y, en ciertas circunstancias, puede adquirir una considerable estabilidad” (ibid.).

¿Sor Juana ignoraba que esta fuerza hegemónica era un "significante vacío”, como lo llama Laclau, o algún nombre sin concepto? Tal vez no, porque en otros textos no sólo habla de las "sonoras cláusulas" del príncipe que encierran a la multitud sino también de sus "dulces voces" que, como los "silbos" del pastor, la "llaman" y la "encantan" (374, 33-63). Como religiosa, ella sabía que en el principio, o en arjê, se encontraba el Verbum o el Lógos. Y sabía incluso que esta palabra era anterior a cualquier concepto, como lo sugiere en un villancico a través de una referencia al misterio de la encarnación:

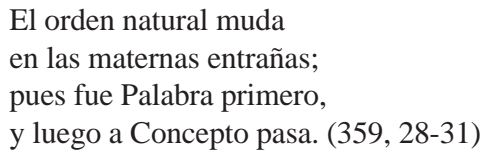

Pero un trabajo sobre la importancia del lógos en los textos de Sor Juana merecería otro artículo.

\section{BiBLIOGRAFÍA}

Agamben, Giorgio. “Fête, deuil, anomie”. État d'exception. Paris: Seuil, 2003. 110-123. Benveniste, Émile. Le vocabulaire des institutions indo-européennes I. Paris: Minuit, 1969. Blánquez Fraile, A., Diccionario Latino-Español, Español-Latino, Barcelona: Sopena, 1975.

Bottéro, Jean. Ecritures. Paris: Le Sycomore, 1982.

Buxó, José Pascal. "Función política de los emblemas en el Neptuno alegórico de Sor Juana Inés de la Cruz". <http://www.cervantesvirtual.com/servlet/SirveObras/ buxó.htm> (22/03/07).

Corominas, Joan. Diccionario etimológico de la lengua castellana. Madrid: Gredos, 1997.

Cruz, Sor Juana Inés de la. Obras completas I, II, III y IV (edición a cargo de Adolfo Méndez Plancarte y de Alberto Salceda para el cuarto tomo). México: FCE, 1995.

Derrida, Jacques. «Foi et savoir». La religion. Jacques Derrida y Gianni Vattimo, eds. Paris: Seuil, 1996. 9-86.

Fernández, Cristina Beatriz. "Variaciones alegóricas y oscuridad simbólica en el Neptuno alegórico de Sor Juana Inés de la Cruz”. Cuadernos para investigación de la literatura hispánica 23 (1998): 311-319.

\footnotetext{
Revista Iberoamericana, Vol. LXXVI, Núms. 232-233 Julio-Diciembre 2010, 957-971 
Freud, Sigmund, La interpretación de los sueños. Barcelona: Planeta/Agostini, 1982.

Foucault, Michel. “Omnes et singulatim (vers une critique de la raison politique)”. Dits et écrits IV. Paris: Gallimard, 1994. 134-161

Gaffiot, Félix, Dictionnaire latin-français. Paris: Hachette, 1934.

Grossi, Verónica. Sigilosos v(u)elos epistemológicos en Sor Juana Inés de la Cruz. Madrid/Frankfurt: Iberomaericana/Vervuert, 2007.

Hinojo, Gregorio. “Fuentes clásicas y renacentistas del Neptuno alegórico”. Nova tellus, Anuario del Centro de Estudios Clásicos 21 (2003): 177-202.

Laclau, Ernesto. La razón populista. Buenos Aires: FCE, 2005.

León, Fray Luis de. De los nombres de Cristo [1587]. Madrid: Cátedra, 1997.

Paz, Octavio. Sor Juana Inés de la Cruz o las trampas de la fe. Barcelona: Seix Barral, 1982.

Scavino, Dardo. "Sor Juana Inés de la Cruz y las prisiones del príncipe”. Escrituras del encierro en América latina. Tomo IV. Isabelle Tauzin, ed. Bordeaux: Presses Universitaires de Bordeaux, 2007. 151-187.

Schmitt, Carl. Théologie politique [1922]. Paris: Gallimard, 1988.

Wissmer, Jean-Michel. La religieuse mexicaine. Genève: Metropolis, 2000.

\begin{tabular}{l} 
ISSN 2154-4794 (Electrónico) \\
\hline
\end{tabular} 
